\title{
Assessing Consumer Demand for Georgia Lavender-Based Products
}

\author{
Joshua Berning ${ }^{1 * \star(D D}$, Benjamin Campbell ${ }^{2}$ and Joshua Buttshaw ${ }^{2}$ \\ ${ }^{1}$ Department of Agricultural and Resource Economics, Colorado State University, USA and ${ }^{2}$ Department of Agricultural and \\ Applied Economics, University of Georgia, USA \\ *Corresponding author. Email: joshua.berning@colostate.edu
}

\begin{abstract}
To further improve the understanding of promoting locally grown lavender, we examine consumer willingness to pay (WTP) for three lavender-based products: lavender bundles, culinary lavender, and lavender oil. We evaluate an online sample located in the southeast using a double-bounded dichotomous choice contingent valuation survey. Lavender bundles have the highest WTP, followed by oil and culinary lavender. Certain marketing factors result in higher WTP, including product familiarity, familiarity with the Georgia Grown program, and shopping frequency at farmers' markets. This study provides a better understanding of the opportunity for small-scale farmers to market specialty crops such as lavender.
\end{abstract}

Keywords: contingent valuation survey; lavender products; small farmers; willingness to pay

JEL Classifications: Q13; C93

\section{Introduction}

The market share of locally grown has increased substantially over recent years (Reynolds-Allie et al., 2013; Low et al., 2015; Vogel and Low, 2015; Ekanem et al., 2016). Although the definition of local varies, consumers often place a higher value on locally grown as well (Onozaka and McFadden, 2011; Darby et al., 2008) and farmers are typically able to retain a greater share of consumer expenditures for locally grown (Zepeda and Li, 2006; Darby et al., 2008; Starr et al., 2003), making it an appealing option for some farmers. Given its marketing potential, local food marketing has attracted significant attention in the literature (Palma et al., 2013); however, less work has been done on the marketing of locally grown horticulture and horticultural products (Palma and Ward, 2010; Rihn et al., 2016).

The purpose of this project is to contribute to understanding the marketing of locally grown horticultural products, specifically focusing on lavender and lavender-based products. As smallscale producers look to increase profitability, there has been increasing interest in growing herbs, such as lavender (Rogers and Kerr, Jr. 1995; Gao and Bergefurd, 1998; Adam, 2006). Lavender is a versatile perennial that is durable, drought resistant, and deer resistant. Commercially, lavender can provide a host of products, including fresh cut flowers, dried lavender bundles, personal care products, and culinary use and essential oils manufacturing. Specialty crops, such as lavender, can provide additional income as well as help to diversify and reduce risks due to price fluctuations with more traditional cash crops or other ventures. Furthermore, lavender farms can operate as agritourism venues.

Given consumer preferences for locally grown, flowering plants, such as lavender, could provide a viable specialty crop for small-scale farmers. It is essential, however, for small-scale growers 
to understand market demand for specialty crops first (Reynolds-Allie, Fields, and Rainey, 2013; Kim, Curtis, and Yeager, 2014) as this can help reduce producers' risk a priori (Rihn et al., 2016).

To date, the few studies that evaluate consumer preferences for local horticulture have provided mixed findings. Yue et al. (2011) examine consumer interest in locally grown ornamental, vegetable, and herb transplants using an internet sample representing four states in the US. Although they find lower consumer interest in organic production, they find significantly higher consumer interest in locally grown products. At the same time, looking at a sample of respondents in Maine, Hawkins et al. (2012) find consumers were willing to pay $10 \%$ more for organic ornamental, vegetable, and herb plants, whereas consumers were less interested in local origins. Also, Rihn et al. (2016) find a positive effect of both organic production methods and in-state origins on survey participants' likelihood to purchase fruit producing plants and indoor foliage.

The few studies examining the marketing of local horticultural products provide mixed findings as well. Collart et al. (2013) examine consumer willingness to pay (WTP) of Texas consumers for two-state ornamental brands. They find that the purchase frequency strongly predicted WTP, but a state marketing campaign had no effect on consumers' preferences. In their assessment of consumers in Florida, Khachatryan et al. (2018) find that local production has a positive impact on purchase likelihood for fruit producing plants. Furthermore, a state marketing program seems to enhance purchase likelihood for consumers that viewed local as good for the economy.

Our research study focuses on Georgia-grown lavender, where there has been growing interest in cultivating commercial lavender. Although lavender is a popular product in the US and abroad, it has not been traditionally grown for commercial purposes in Georgia. As such, little is known about how to market Georgia-grown lavender. Furthermore, to the best of our knowledge, there are no studies examining consumer demand for lavender in the US.

To evaluate the potential value of growing lavender for small-scale farmers, we estimate consumer WTP for three lavender-based products requiring different levels of processing: dried lavender bundles, culinary lavender, and lavender oil ${ }^{1}$. We survey an online sample of consumers residing in the southeast. We compile their demographic information, shopping behavior, and preferences for various marketing strategies. We then use a double-bounded dichotomous choice contingent valuation method to estimate their WTP for the three products. The results of our study provide several insights regarding lavender marketing.

First, we find that consumers that are more familiar with the Georgia Grown state marketing program exhibit a higher WTP for the Georgia-grown lavender products. This suggests that state branding could be an effective marketing tool for lavender growers. Similarly, consumers that shop at farmers' markets (FMs) more frequently have a higher WTP, suggesting that this distribution channel might be a benefit for locally grown lavender as well. At the same time, consumers that view local as a smaller geographic area are not necessarily willing to pay more than those that view local as being from a broader geographic area. Altogether, there may be an opportunity for small-scale growers to market Georgia-grown lavender to a wider audience than just those in their immediate region.

We find that the biggest contributor to higher WTP is product familiarity. That is, the more familiar the person is with the product, the higher is their WTP. As a non-trivial share of consumers reported not knowing the lavender products to begin with, this suggests that farmers can benefit from introducing potential consumers to their various lavender products and educating them on the benefits of using lavender products.

Finally, we find the WTP for lavender bundles to be the largest, followed by lavender oil and culinary lavender. Lavender oil is more costly to produce than lavender bundles, which just need to be cut and dried. This may make lavender oil less profitable as an investment for small-scale

\footnotetext{
${ }^{1}$ The lavender bundles contained 30 dried lavender stems tied in a bouquet. The lavender oil is typically extracted from lavender plants and comes in a liquid. The culinary lavender are petals taken from the lavender plants and stored in a container.
} 
Table 1. Demographic variable summary statistics

\begin{tabular}{|c|c|c|c|c|c|}
\hline Variable & Obs & Mean & Std. Dev. & Min & Max \\
\hline Age & 951 & 45.96 & 16.16 & 18 & 93 \\
\hline Gender (female) & 770 & 0.67 & - & - & - \\
\hline Shopper & 951 & 0.79 & - & - & - \\
\hline Educ & 951 & 3.85 & 1.60 & 1 & 8 \\
\hline Children & 936 & 1.71 & 1.06 & 1 & 11 \\
\hline Income & 949 & 3.22 & 2.42 & 0 & 12 \\
\hline $\mathrm{AL}$ & 110 & 0.12 & - & - & - \\
\hline $\mathrm{FL}$ & 114 & 0.12 & - & - & - \\
\hline GA & 508 & 0.53 & - & - & - \\
\hline SC & 110 & 0.12 & - & - & - \\
\hline $\mathrm{TN}$ & 109 & 0.11 & - & - & - \\
\hline
\end{tabular}

producers. Even though culinary lavender does not garner as high WTP, it is also relatively easy to produce and could help diversify a farmers' product offering.

Overall, the results of this study provide a better understanding for small-scale farmers regarding how to market locally grown lavender. Importantly, whereas our WTP appears to be on par with what early adopters are currently charging, farmers need to be aware of their own production and distribution costs as well as their target consumer market.

\section{Data}

We surveyed roughly 1,000 people from five states in the Southeastern United States in the fall of 2017 using the online survey service provider Toluna. The survey design was pre-tested on several groups of graduate students before submitting the final design for IRB approval. The final survey took approximately 15-20 minutes to complete. We obtained 951 completed surveys.

We asked respondents about their demographics, preferences for certain marketing tactics, and their WTP for three lavender-based products: lavender bundles, lavender oil, and culinary lavender. The lavender bundles contained 30 dried stems in a bundle, and we provided a picture as an example. The lavender oil was 0.5 ounces, which is a common size for such oils, and we provided a picture of non-branded bottle to give respondents an idea of the container size. The culinary lavender was also a 0.5 -ounce jar, and we provided a picture of a non-branded container ${ }^{2}$.

The survey sample age ranged from 18 to 93 with the average age of 46 (Table 1). The majority of the sample was female (67\%) and the primary household shopper (78\%). The average education level (3.8) corresponds to having some college. There was an average of 1.7 children per household, and the average household income level (3.0) corresponds to $\$ 50 \mathrm{k}-\$ 75 \mathrm{k}$. About $79 \%$ of the respondents self-reported as the primary shopper in the household. Women were oversampled as it has been shown they are the generally the primary shopper in the household (Flagg et al., 2013; Wolfe, 2013; Zepeda, 2009).

The median household income in the Southeast is around $\$ 50,000$ and the median age around 39 (United States Census Bureau, 2019a). The Southeastern census average falls within the

\footnotetext{
${ }^{2}$ Culinary lavender is typically sold by weight. However, as survey respondents could not hold or touch the product, we provided a reference based on the volume size of a typical container.
} 
categorical range for our sample, but our sample's age of 46 is older than the Southeastern census median. However, our sample does not include people under the age of 18, which represent $20-25 \%$ of the population of most states (United States Census Bureau, 2019b). Most respondents were from Georgia (53\%), and the remainder was evenly from Alabama, Florida, South Carolina, and Tennessee. As the target market of our growers is in-state, we emphasized greater response rate from Georgia. The other four states are those bordering Georgia.

During our survey pre-testing, several respondents reported being unfamiliar with the lavender-based products in our survey. This could have an impact on consumer interest, therefore, WTP for such products. To evaluate how consumer awareness of these lavender products impacts WTP, we asked a series of questions about how often the respondent purchased lavender bundles, lavender oil, and culinary lavender (see Appendix for the questions).

As can be seen, the share of respondents that reported never purchasing bundles, oil, and culinary lavender was $67 \%, 48 \%$, and $68 \%$, respectively (Table 2 ). This could be a challenge for growers if this is because consumers do not like the products or find them to be too costly. Alternatively, it could also be an opportunity for growers to gain market share if they can convince consumers of the potential benefits. To that point, we found that around $9 \%$ of respondents did not know about lavender bundles, 5\% did not know about oil, and 11\% did not know about culinary lavender (Table 2). This suggests an opportunity for growers to market to consumers that are unaware of their products. There is also the potential opportunity to increase purchase frequency as only a small share of respondents report purchasing any of the products more than 12 times a year.

We also attempt to evaluate how various marketing tactics might affect respondents in our survey. One potential tactic we consider is the state marketing program, Georgia Grown, which seeks to promote Georgia-grown and produced products. Producers can join the program at different cost levels (including a no-cost tier) and receive different amounts of marketing support. To evaluate survey respondents, we measure how familiar they are with the program (see Appendix for the question). The majority of respondents (57\%) had never heard of the program, and over $16 \%$ had heard of the program but did not know what it was. If we look at this same data for Georgia residents, $45 \%$ had never heard of the program and $20 \%$ had heard of it but did not know what it was. So, whereas out of state respondents are less familiar with the program, a significant share of in-state respondents is also unfamiliar with the program. We assume that consumers that are more familiar of the Georgia Grown program will be more interested in buying Georgia-grown products. At the same time, consumers may not have to know the state marketing program to have a higher WTP for Georgia-grown products. That is, they may be interested in products that they know are state grown regardless of the marketing program.

Another tactic for growers and sellers is to market their products at local FMs. To evaluate this strategy, we ask how often respondents shop at FMs during the summer, the peak operating time for most markets. The majority of respondents shop at FMs at least one time a summer (78\%). Importantly, nearly $20 \%$ shop at least six times a summer or more, which is roughly every other week. Clearly, selling at FMs is beneficial only if consumer shop frequently at FMs and have a sufficient WTP. We explore this question more in our analysis.

Finally, previous studies have found a higher WTP for locally grown products (Darby et al., 2008; Onozaka and McFadden, 2011; Yue and Tong, 2009; Katz, Campbell, and Liu, 2019; Chakrabarti, Campbell, and Shonkwiler, 2019). However, this may be dependent on how the consumer defines local. That is, some people may view local as coming from a group of states in a region (i.e., southeast). Others may view local as coming from their town. If the definition of local impacts WTP for lavender, growers may need to be cognizant of their distribution strategy if they want to capitalize on locally grown lavender. To evaluate consumer perception of local, we ask consumers to rank the largest geographic area that they would still consider to be "locally grown" (see Appendix for the question). 
Table 2. Marketing variable statistics

\begin{tabular}{|c|c|c|c|}
\hline & Variable & Obs & Mean \\
\hline \multicolumn{4}{|c|}{ Purchase frequency } \\
\hline \multirow[t]{5}{*}{ Bundles } & I do not know what this is & 938 & 0.093 \\
\hline & Never & 938 & 0.670 \\
\hline & 1-4 times a year & 938 & 0.146 \\
\hline & 5-11 times a year & 938 & 0.058 \\
\hline & 12 or more times a year & 938 & 0.034 \\
\hline \multirow[t]{5}{*}{ Oil } & I do not know what this is & 945 & 0.054 \\
\hline & Never & 945 & 0.486 \\
\hline & 1-4 times a year & 945 & 0.305 \\
\hline & 5-11 times a year & 945 & 0.108 \\
\hline & 12 or more times a year & 945 & 0.048 \\
\hline \multirow[t]{5}{*}{ Culinary } & I do not know what this is & 947 & 0.112 \\
\hline & Never & 947 & 0.682 \\
\hline & 1-4 times a year & 947 & 0.120 \\
\hline & 5-11 times a year & 947 & 0.061 \\
\hline & 12 or more times a year & 947 & 0.024 \\
\hline \multirow[t]{5}{*}{ GA grown } & I have not heard of it & 940 & 0.571 \\
\hline & I have heard of it, but do not know what it is & 940 & 0.165 \\
\hline & Somewhat familiar with the program & 940 & 0.128 \\
\hline & I am familiar with the program & 940 & 0.072 \\
\hline & I am very familiar with the program & 940 & 0.064 \\
\hline \multirow[t]{5}{*}{ Farmers mkts } & 0 times a summer & 951 & 0.227 \\
\hline & 1-2 times a summer & 951 & 0.309 \\
\hline & 3-5 times a summer & 951 & 0.266 \\
\hline & $6-12$ times a summer & 951 & 0.131 \\
\hline & 13 times or more a summer & 951 & 0.066 \\
\hline \multirow[t]{6}{*}{ Local } & The town you live in & 951 & 0.144 \\
\hline & The county you live in & 951 & 0.204 \\
\hline & The region you live in & 951 & 0.299 \\
\hline & The state you live in & 951 & 0.217 \\
\hline & The southeast & 951 & 0.062 \\
\hline & The United States & 951 & 0.075 \\
\hline
\end{tabular}

\section{Methods}

To examine the WTP of survey respondents in our sample, we use a double-bound contingent valuation experiment (Hanemann et al., 1991). For each product (bundles, oil, and culinary), survey respondents were asked if they would be willing to pay some initial bid for the lavender product. If the respondent rejected the initial bid, they were asked if they would be willing to pay 
Table 3. Survey experiment treatment prices

\begin{tabular}{|c|c|c|c|c|}
\hline \multirow[b]{2}{*}{ Product } & \multirow[b]{2}{*}{ Treatment } & \multirow[b]{2}{*}{ Initial Bid } & \multicolumn{2}{|c|}{ Follow-Up Bid } \\
\hline & & & Reject & Accept \\
\hline \multirow[t]{3}{*}{ Bundles } & Low & $\$ 8$ & $\$ 6$ & $\$ 10$ \\
\hline & Average & $\$ 12$ & $\$ 10$ & $\$ 14$ \\
\hline & High & $\$ 16$ & $\$ 14$ & $\$ 18$ \\
\hline \multirow[t]{3}{*}{ Culinary } & Low & $\$ 4$ & $\$ 3$ & $\$ 5$ \\
\hline & Average & $\$ 6$ & $\$ 5$ & $\$ 7$ \\
\hline & High & $\$ 8$ & $\$ 7$ & $\$ 9$ \\
\hline \multirow[t]{3}{*}{ Oil } & Low & $\$ 8$ & $\$ 6$ & $\$ 10$ \\
\hline & Average & $\$ 12$ & $\$ 10$ & $\$ 14$ \\
\hline & High & $\$ 16$ & $\$ 14$ & $\$ 18$ \\
\hline
\end{tabular}

Table 4. Bundle experiment results summary

\begin{tabular}{|c|c|c|c|c|c|c|}
\hline \multirow{2}{*}{$\frac{n}{321}$} & \multirow{2}{*}{$\frac{\text { Initial Bid }}{\$ 8.00}$} & \multicolumn{2}{|c|}{ Decision/\% } & \multirow{2}{*}{$\frac{\text { Follow-Up Bid }}{\$ 6.00}$} & \multicolumn{2}{|c|}{ Decision/\% } \\
\hline & & Reject & $54 \%$ & & Reject & $56 \%$ \\
\hline & & & & & Accept & $44 \%$ \\
\hline & & Accept & $46 \%$ & $\$ 10.00$ & Reject & $46 \%$ \\
\hline & & & & & Accept & $54 \%$ \\
\hline \multirow[t]{4}{*}{320} & $\$ 12.00$ & Reject & $62 \%$ & $\$ 10.00$ & Reject & $68 \%$ \\
\hline & & & & & Accept & $32 \%$ \\
\hline & & Accept & $38 \%$ & $\$ 14.00$ & Reject & $42 \%$ \\
\hline & & & & & Accept & $58 \%$ \\
\hline \multirow[t]{4}{*}{309} & $\$ 16.00$ & Reject & $72 \%$ & $\$ 14.00$ & Reject & $83 \%$ \\
\hline & & & & & Accept & $17 \%$ \\
\hline & & Accept & $28 \%$ & $\$ 18.00$ & Reject & $52 \%$ \\
\hline & & & & & Accept & $48 \%$ \\
\hline
\end{tabular}

for a lesser bid. If they accepted the initial bid, they were asked if they would be willing to pay for a higher bid.

We obtained a range of initial retail prices for each product from interviews with Georgia lavender growers. Based on those prices, we created three treatments for each product representing a low, average, and high price (Table 3). For example, a survey respondent in the high bundle treatment would be initially offered a price of $\$ 16 /$ bundle. If they rejected this bid, the follow-up would be $\$ 14 /$ bundle. If they accepted the bid, the follow-up would be $\$ 18 /$ bundle. The range of initial bids and follow-up bids was chosen to capture a wide range of potential WTP responses, and the current market prices are roughly equal to the average initial bid. We randomly assigned survey participants to one of the three price treatment levels for each product, and the products were presented in a random order.

There were roughly the same number of respondents for each treatment (Table 4). With lavender bundles, the low price initial bid $(\$ 8)$ had the largest acceptance at $46 \%$, and the high price 
Table 5. Culinary experiment results summary

\begin{tabular}{|c|c|c|c|c|c|c|}
\hline \multirow{2}{*}{$\frac{n}{320}$} & \multirow{2}{*}{$\frac{\text { Initial Bid }}{\$ 4.00}$} & \multicolumn{2}{|c|}{ Decision/\% } & \multirow{2}{*}{$\frac{\text { Follow-Up Bid }}{\$ 3.00}$} & \multicolumn{2}{|c|}{ Decision/\% } \\
\hline & & Reject & $38 \%$ & & Reject & $73 \%$ \\
\hline & & & & & Accept & $27 \%$ \\
\hline & & Accept & $62 \%$ & $\$ 5.00$ & Reject & $40 \%$ \\
\hline & & & & & Accept & $60 \%$ \\
\hline \multirow[t]{4}{*}{317} & $\$ 6.00$ & Reject & $51 \%$ & $\$ 5.00$ & Reject & $72 \%$ \\
\hline & & & & & Accept & $28 \%$ \\
\hline & & Accept & $48 \%$ & $\$ 7.00$ & Reject & $44 \%$ \\
\hline & & & & & Accept & $56 \%$ \\
\hline \multirow[t]{4}{*}{314} & $\$ 8.00$ & Reject & $63 \%$ & $\$ 7.00$ & Reject & $84 \%$ \\
\hline & & & & & Accept & $16 \%$ \\
\hline & & Accept & $37 \%$ & $\$ 9.00$ & Reject & $43 \%$ \\
\hline & & & & & Accept & $57 \%$ \\
\hline
\end{tabular}

Table 6. Oil experiment results summary

\begin{tabular}{|c|c|c|c|c|c|c|}
\hline \multirow{2}{*}{$\frac{n}{314}$} & \multirow{2}{*}{$\frac{\text { Initial Bid }}{\$ 8.00}$} & \multicolumn{2}{|c|}{ Decision/\% } & \multirow{2}{*}{$\frac{\text { Follow-Up Bid }}{\$ 6.00}$} & \multicolumn{2}{|c|}{ Decision/\% } \\
\hline & & Reject & $54 \%$ & & Reject & $59 \%$ \\
\hline & & & & & Accept & $41 \%$ \\
\hline & & Accept & $46 \%$ & $\$ 10.00$ & Reject & $54 \%$ \\
\hline & & & & & Accept & $46 \%$ \\
\hline \multirow[t]{4}{*}{322} & $\$ 12.00$ & Reject & $65 \%$ & $\$ 10.00$ & Reject & $72 \%$ \\
\hline & & & & & Accept & $28 \%$ \\
\hline & & Accept & $35 \%$ & $\$ 14.00$ & Reject & $53 \%$ \\
\hline & & & & & Accept & $47 \%$ \\
\hline \multirow[t]{4}{*}{315} & $\$ 16.00$ & Reject & $73 \%$ & $\$ 14.00$ & Reject & $88 \%$ \\
\hline & & & & & Accept & $12 \%$ \\
\hline & & Accept & $27 \%$ & $\$ 18.00$ & Reject & $40 \%$ \\
\hline & & & & & Accept & $60 \%$ \\
\hline
\end{tabular}

initial bid (\$16) had the lowest acceptance at $28 \%$. If a respondent rejected the initial bid, they were more likely to reject the follow-up bid as well. If the respondent accepted the initial bid, they were more likely to accept the follow-up bid, except in the high price treatment. Still, the percentage that accepts and rejects the follow-up bid was similar in that treatment.

With culinary lavender, we had a fairly uniform distribution of treatments and we find similar results (Table 5). The low price initial bid had the highest acceptance, and the high price initial bid had the lowest acceptance. Furthermore, reject-reject and accept-accept were the most probable for each treatment.

The lavender oil (Table 6) tended to have a greater percentage of rejection for the follow-up bid on each treatment, with the exception of the high price treatment following an initial accept. With this group, $27 \%$ accepted the initial bid and $60 \%$ accepted the higher follow-up bid. 
Table 7. Basic model estimates

\begin{tabular}{lccc}
\hline & \multicolumn{3}{c}{ Product } \\
\cline { 2 - 4 } variable & Bundles & Culinary & Oil \\
\hline WTP & $9.971^{\star \star \star}$ & $5.556^{\star \star \star}$ & $9.508^{\star \star \star}$ \\
\hline Cl & {$[9.540-10.40]$} & {$[5.324-5.788]$} & {$[9.058-9.959]$} \\
\hline Observations & 949 & 948 & 950 \\
\hline Log-lik & -1281 & -1273 & -1251 \\
\hline
\end{tabular}

${ }^{\star \star \star} P<0.001,{ }^{\star \star} P<0.01,{ }^{\star} P<0.05$

To analyze these responses, we specify WTP for each person $i$ for each of the $j$ products as a linear function:

$$
W T P_{i j}=z_{i}^{\prime} \beta+\varepsilon_{i j},
$$

where $z$ includes a constant term, demographic characteristics, and responses to the previously discussed survey questions, and $\varepsilon_{i j} \sim N\left(0, \sigma^{2}\right)$. We then use each person's response to their first bid $\left(t^{1}\right)$ and second bid $\left(t^{2}\right)$ to define WTP intervals. Defining a person's response (Yes or No) to each bid as \{response 1, response 2\}, we can infer that the WTP for each person lies in one of the four intervals:

$$
\begin{aligned}
& \left\{\text { Yes, No\}: } \mathrm{t}^{1}<\mathrm{WTP}<\mathrm{t}^{2},\right. \\
& \left\{\text { Yes, Yes\}: } \mathrm{t}^{2}<\mathrm{WTP}<\infty,\right. \\
& \{N o, Y e s\}: \mathrm{t}^{2}<\mathrm{WTP}<\mathrm{t}^{1}, \\
& \left\{\text { No,No\}:0<WTP }<\mathrm{t}^{2} .\right.
\end{aligned}
$$

If we assume each bid follows the same valuation function, we can define these intervals as a likelihood function (Lopez-Feldman, 2012), such that, for each product, we have:

$$
L(\beta, \sigma)=\sum_{i=1}^{N}\left[\begin{array}{c}
d_{i}^{y n} \ln \left(\Phi\left(z_{i}^{\prime} \frac{\beta}{\sigma}-\frac{t^{1}}{\sigma}\right)-\Phi\left(z_{i}^{\prime} \frac{\beta}{\sigma}-\frac{t^{2}}{\sigma}\right)\right)+d_{i}^{y y} \ln \left(\Phi\left(z_{i}^{\prime} \frac{\beta}{\sigma}-\frac{t^{2}}{\sigma}\right)\right)+ \\
d_{i}^{n y} \ln \left(\Phi\left(z_{i}^{\prime} \frac{\beta}{\sigma}-\frac{t^{2}}{\sigma}\right)-\Phi\left(z_{i}^{\prime} \frac{\beta}{\sigma}-\frac{t^{1}}{\sigma}\right)\right)+d_{i}^{n n} \ln \left(1-\Phi\left(z_{i}^{\prime} \frac{\beta}{\sigma}-\frac{t^{2}}{\sigma}\right)\right)
\end{array}\right],
$$

where $d$ are indicator variables that take a value of zero or one depending on each person's responses, the superscript values $(y, n)$ identify the set \{response 1 , response 2$\}$, and $\Phi$ signifies a normal distribution. We estimate equation (2) using maximum likelihood to obtain parameter estimates $\beta$ and standard deviation $\sigma^{3}$

\section{Results}

\subsection{Initial results}

We first estimate equation (1) with no covariates. The WTP for each product is thus represented by the constant term. The estimated WTP for each of the products is below the average initial bid from our three treatments (Table 7). The bundles have the highest WTP (\$9.97), although they are not statistically larger than the WTP for oil (\$9.51). Still, one bundle of lavender is typically cheaper to produce than one 0.5 -ounce bottle of oil, which is a relevant consideration when deciding which product to market to consumers. Culinary lavender has the lowest WTP $(\$ 5.56)$.

Overall, it seems growers and processors are currently charging a price for their products that are on par with consumer WTP, if not a little more (see Table 3 for the range of prices). From a

\footnotetext{
${ }^{3}$ We use the command doubleb in Stata 13 written by Lopez-Feldman to estimate our models.
} 

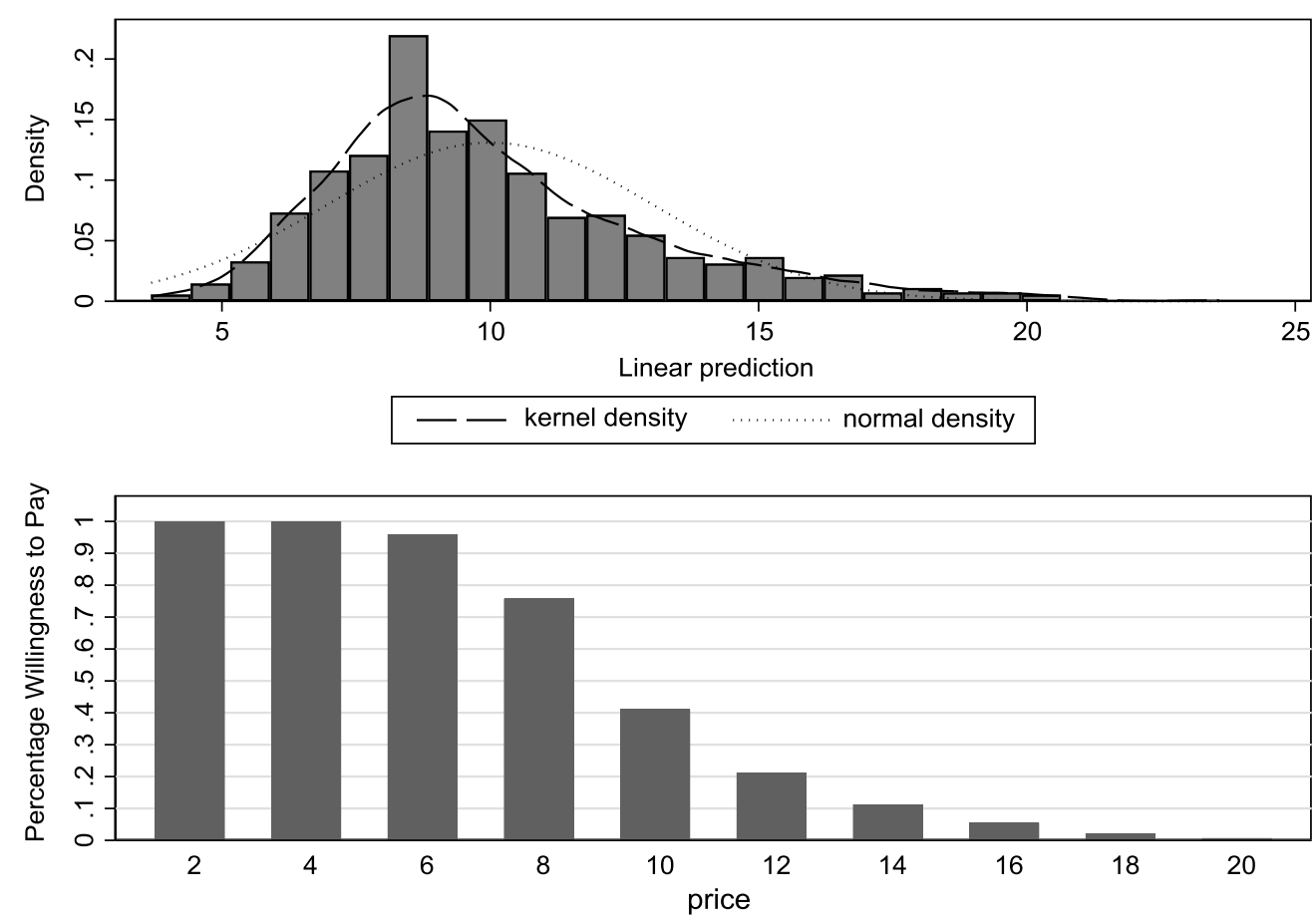

Figure 1. Bundle willingness to pay histogram.

marketing perspective, there is likely to be greater opportunity in segmenting the market for lavender products. As such, we further explore various segments for each product. To this end, we estimate the WTP for each product including all the demographic variables.

\subsection{Bundles}

After including demographic variables in our bundles model, we lose 210 observations, but the log-likelihood increases over our basic model, suggesting a better specified model. We calculate the WTP for the sample using parameter estimates and mean values for all demographic variables as $z_{i}^{\prime} \beta$. The WTP is $\$ 10.01$, which is statistically significant but not different from the base model.

To further examine the heterogeneity of our results, we predict the WTP for lavender bundles for each person and plot the WTP distribution (Figure 1, top panel). Assuming a normal distribution, the sample average WTP is $\$ 9.92$, but it appears that the distribution is not normally distributed and there is significant heterogeneity in WTP. The kernel density is skewed to the right, with some people having a WTP greater than $\$ 22$. At the same time, we find some people with a WTP below $\$ 3$.

To provide some context for this distribution, we plot the cumulative WTP at an interval of prices (Figure 1, bottom panel). Roughly $99.8 \%$ of our sample is willing to pay $\$ 4$ for the lavender bundles. However, as we increase WTP to $\$ 8$, we drop to $75.7 \%$ of the sample. The biggest drop occurs as we go from $\$ 8$ to $\$ 10$, which is equivalent to an arc elasticity of -2.67 . These data suggest that certain people have a much higher WTP for the product, but, overall, general demand is elastic at around $\$ 10$. Consequently, growers might need to be cautious about pricing beyond the average WTP.

Looking at the results of our parameter estimates, younger people had a significantly higher WTP (Table 8, column 1). A model including a quadratic term for age was also estimated, 
Table 8. Full model results

\begin{tabular}{|c|c|c|c|}
\hline & \multicolumn{3}{|c|}{ Product } \\
\hline & Bundles & Culinary & Oil \\
\hline \multirow[t]{2}{*}{ Age } & $-0.0588^{\star \star \star}$ & $-0.0346^{\star * *}$ & -0.0206 \\
\hline & -0.00 & -0.00 & -0.21 \\
\hline \multirow[t]{2}{*}{ Female } & 0.122 & 0.432 & 0.247 \\
\hline & -0.808 & -0.162 & -0.636 \\
\hline \multirow[t]{2}{*}{ Children } & -0.203 & $0.310^{\star}$ & 0.416 \\
\hline & -0.38 & -0.02 & -0.07 \\
\hline \multirow[t]{2}{*}{ Primary shopper } & -0.314 & -0.0428 & 0.321 \\
\hline & -0.57 & -0.90 & -0.58 \\
\hline \multirow[t]{2}{*}{ GA resident } & 0.173 & -0.131 & 0.275 \\
\hline & -0.71 & -0.64 & -0.57 \\
\hline \multirow[t]{2}{*}{ Unknown product } & -1.539 & -0.81 & -1.461 \\
\hline & -0.06 & -0.07 & -0.25 \\
\hline \multirow[t]{2}{*}{ Purchase freq } & $1.675^{\star \star \star}$ & $0.877^{\star \star \star}$ & $1.835^{\star \star \star}$ \\
\hline & -0.00 & -0.00 & -0.00 \\
\hline \multirow[t]{2}{*}{ Farmers mkts } & $0.681^{\star \star \star}$ & $0.449^{\star \star \star}$ & $0.534^{\star}$ \\
\hline & -0.00 & -0.00 & -0.01 \\
\hline \multirow[t]{2}{*}{ Local definition } & 0.252 & $0.222^{\star}$ & 0.103 \\
\hline & -0.12 & -0.02 & -0.55 \\
\hline \multirow[t]{2}{*}{ GA grown } & $0.947^{\star \star \star}$ & $0.278^{\star}$ & $0.883^{\star \star \star}$ \\
\hline & -0.00 & -0.04 & -0.00 \\
\hline \multirow[t]{2}{*}{ Education } & -0.0419 & -0.0462 & -0.078 \\
\hline & -0.79 & -0.64 & -0.64 \\
\hline \multirow[t]{2}{*}{ Income } & $0.291^{\star}$ & $0.164^{\star}$ & $0.293^{\star}$ \\
\hline & -0.02 & -0.03 & -0.02 \\
\hline \multirow[t]{2}{*}{ Constant } & $7.531^{\star \star \star}$ & $3.501^{\star \star \star}$ & $4.035^{\star \star}$ \\
\hline & -0.00 & -0.00 & -0.00 \\
\hline \multirow[t]{2}{*}{ WTP } & $10.01^{\star \star \star}$ & $5.515^{\star \star \star}$ & $9.416^{\star \star \star}$ \\
\hline & -0.23 & -0.13 & -0.24 \\
\hline Observations & 739 & 744 & 746 \\
\hline Log-lik & -925.9 & -923.8 & -890.5 \\
\hline
\end{tabular}

but it did not significantly affect the model results and the term was not statistically significant. Therefore, we deferred to the simpler model. Interestingly, Georgia residents did not have a higher WTP for the lavender bundles. This is relevant, because many growers will initially distribute or sell their product at local venues. From a marketing perspective, there may be no added advantage to just selling locally. There may still be a cost advantage, however, when distributing locally. 


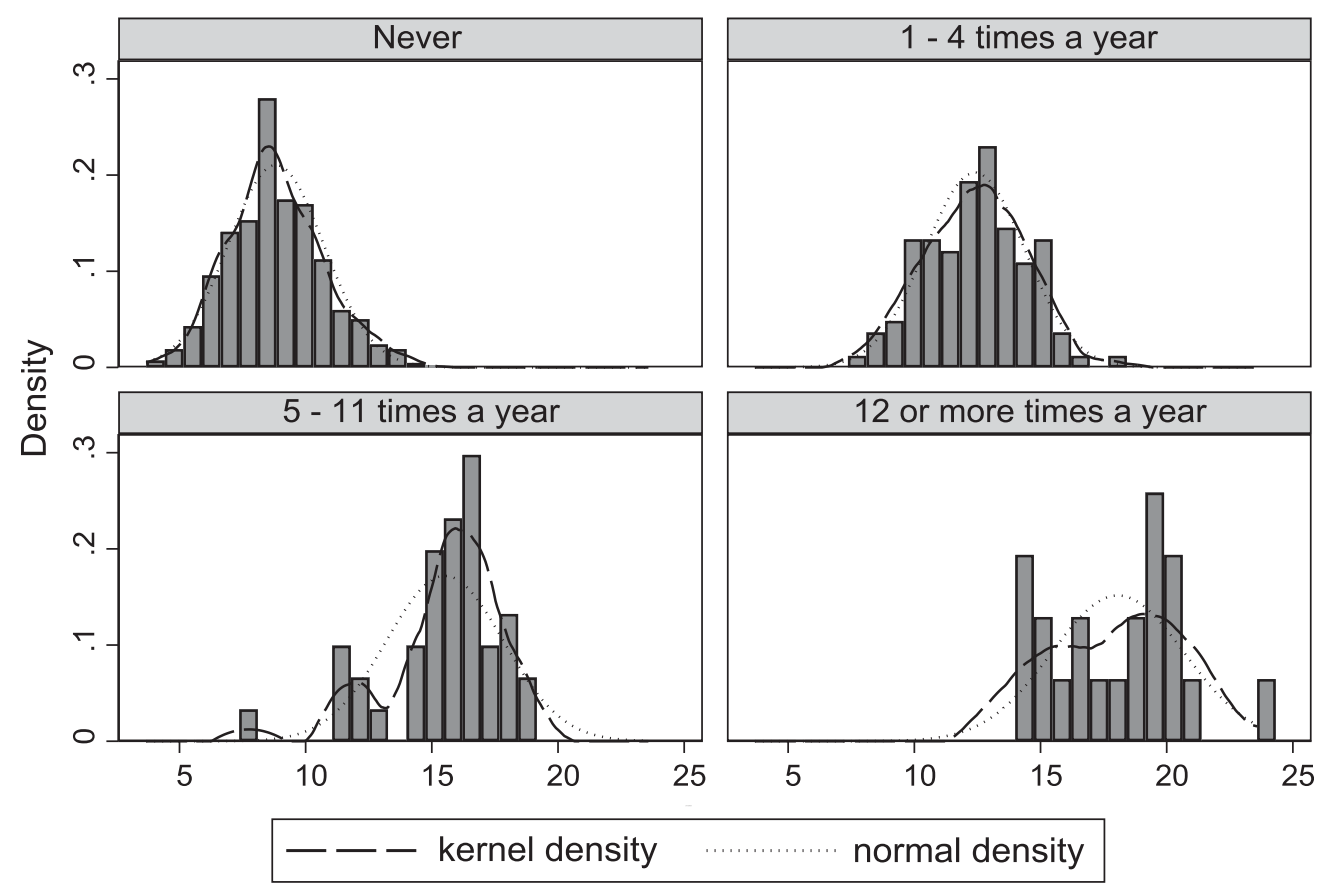

Graphs by freq_bouquet

Figure 2. Bundle willingness to pay histogram by purchase frequency.

We identify people who did not know what lavender bundles were when asked about their frequency of purchase. In particular, the variable unknown is a dummy variable that takes the value 1 when the person responded that they did not know what the product was. As can be seen, people who did not know what lavender bundles were had a lower WTP, although this was not significant at a 5\% $P$-value. Still, building up consumer product knowledge could be beneficial.

With the purchase frequency variable, we aggregate respondents who did not know about the product with those who never buy the product, and both are coded as having zero purchases. The purchase frequency then reports purchase frequency for those who have made lavender bundle purchases. This variable is statistically significant and suggests a $\$ 1.67$ increase in WTP for each step in purchase frequency. Overall, these results indicate that product awareness plays an important role in WTP. To examine this further, we create a WTP histogram for each purchase frequency (Figure 2). Respondents who never purchase lavender bundles have a kernel distribution skewed to the right and a low WTP. As purchase frequency increases, the skewness shifts to the left. Those who buy lavender bundles the most have the highest WTP estimates. There is also more heterogeneity in the WTP with the higher frequency purchase groups. Interestingly, the distribution of WTP estimates of those that never buy lavender bundles overlaps with the distribution of WTP estimates of those who buy lavender bundles the most. So, whereas some people may never buy lavender bundles, they may still have an interest in buying the product. This could indicate that these consumers do not know where to purchase these products or that some other transaction cost inhibits them from making a purchase.

Next, we examine how familiarity with the Georgia Grown program affects WTP. As awareness increases, WTP also increases significantly (Table 8, column 1). This highlights that consumers that are more familiar with this program to enhance Georgia agriculture are more willing to spend on Georgia-grown products. 

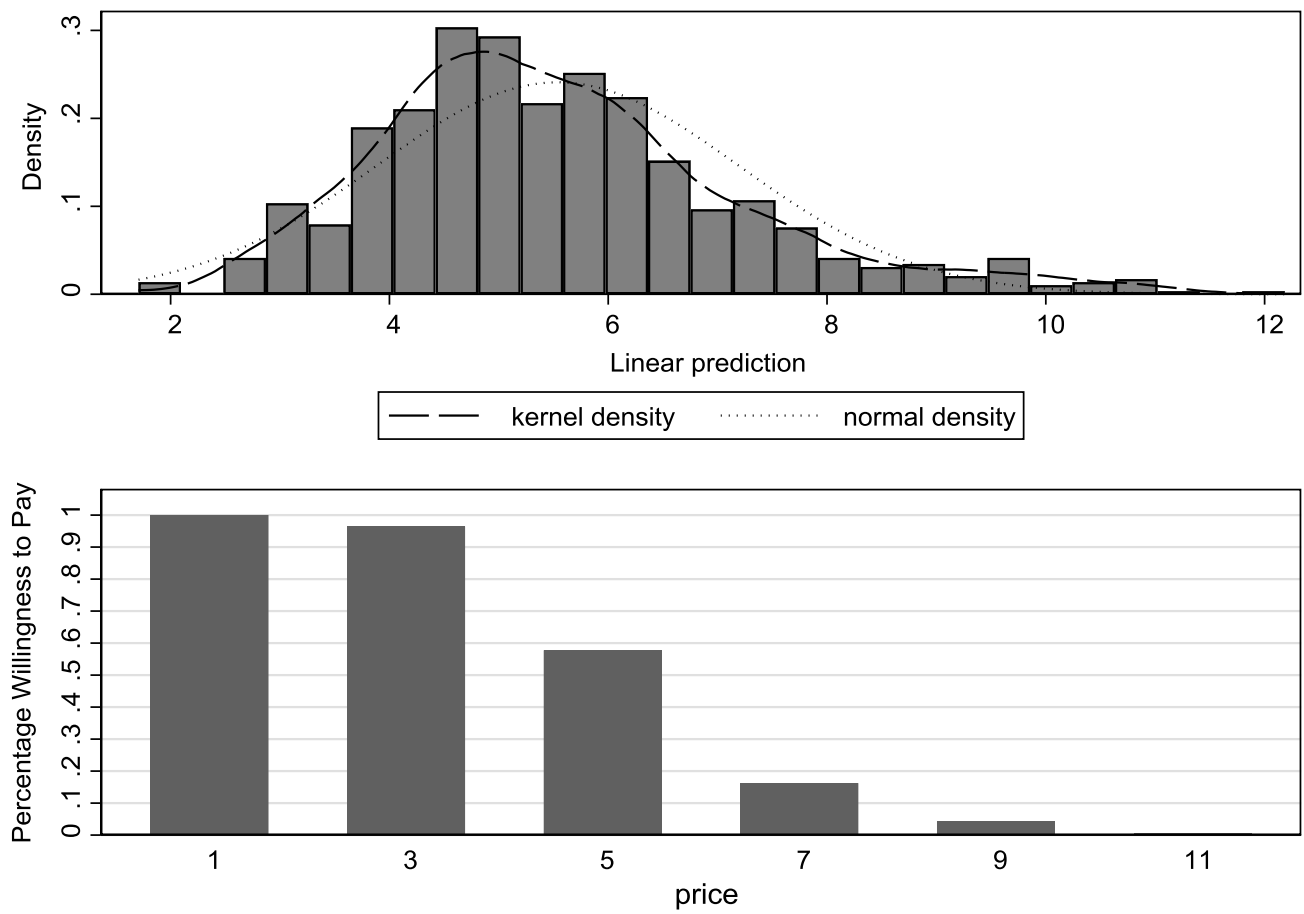

Figure 3. Culinary willingness to pay histogram.

Another segment we evaluate are people that shop more frequently at FMs. We find that as the reported level of participation at FMs increases, so does the WTP for lavender bundles. At the same time, we also find that consumers that identify local as being from a smaller geographic area have no different WTP than consumers that identify local as being from a larger geographic area. This could mean that these consumers prefer products sold in FMs regardless of how they define local. In another way, preferences for FM may not necessarily be driven by preferences for local farmers, but rather preferences for products sold at FMs in general. Altogether, this could indicate that selling at FMs is a preferred distribution channel for lavender growers. Caution is in order, however, as foot traffic at FMs may be limited as are the days and hours of operation.

\subsection{Culinary}

With this model, the calculated WTP is not different from our basic model, and we lose 204 observations due to missing values in our fully specified model. Still, the log-likelihood suggests a better specified model. We again calculate and plot the WTP of the entire sample. The distribution is skewed to the right, with a high over $\$ 12$ and a low below $\$ 2$ (Figure 3, top panel), suggesting significant heterogeneity and a non-normal distribution as well. Around $96 \%$ of the sample is willing to pay $\$ 3$ for the culinary lavender, but that percentage to $57.7 \%$ as WTP goes to $\$ 5$ and $16 \%$ at $\$ 7$ (Figure 3, bottom panel). Similar to lavender bundles, this reveals a highly elastic demand near the average WTP. In particular, the arc elasticity going from $\$ 5$ to $\$ 7$ is -3.37 , suggesting highly an elastic response to price increases above $\$ 5$. The share of people willing to pay $\$ 9$ or more is about $4 \%$.

Looking at the parameter estimates, we find similar results with culinary lavender as we do with bundles (Table 8, column 2). People who did not know what culinary lavender was have a lower WTP, but that value is not significant at a $5 \% P$-value. Again, we find as purchase frequency 


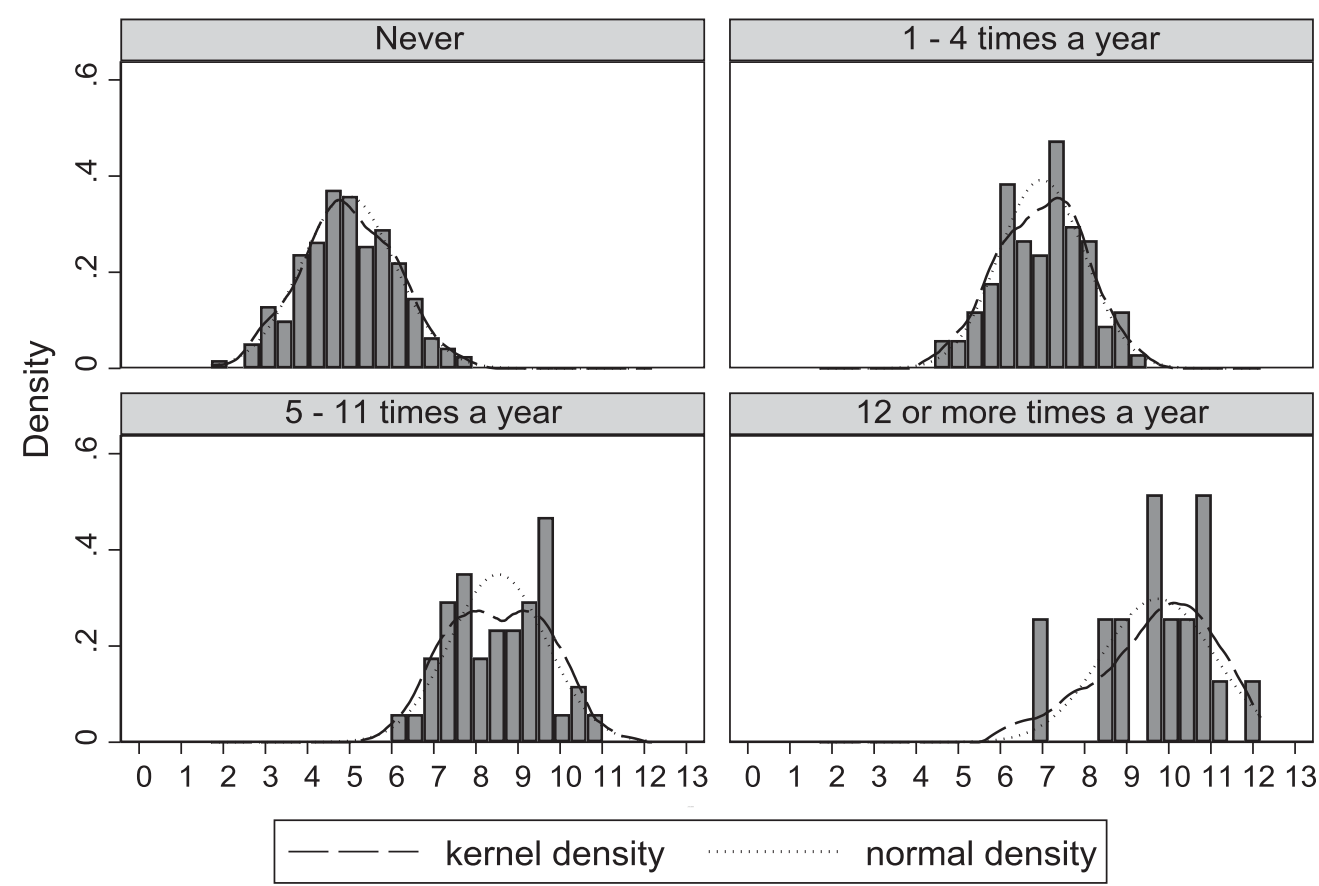

Graphs by freq_bake

Figure 4. Culinary willingness to pay histogram by purchase frequency.

increases, so does the WTP estimate. Separate histograms for these groups are shown in Figure 4. The density of these separate distributions is much more peaked for each category, indicating WTP values that are clustered closely around the median. There is still some overlap between the WTP of those that never buy culinary lavender and those that buy culinary lavender 12 or more times a year. Also, the WTP of the most frequent purchasers is sparser than those that buy culinary lavender infrequently. The opportunity to increase WTP for this product may be more challenging or limited.

The increase in WTP for culinary lavender associated with awareness of the Georgia Grown marketing program is positive, but lower than the increase found with lavender bundles and only significant at the $5 \%$ level (Table 8, column 2). Respondents that shop more at FMs have a higher WTP for culinary lavender as well. At the same time, as respondents' definition of local expands, so does their WTP for culinary lavender. It is not clear why a broader definition of local would correspond to a higher WTP for Georgia-grown culinary lavender.

\subsection{Oil}

For lavender oil, the predicted WTP (\$9.42) is about \$2.5 less than the average initial bid, which was based on grower prices (Table 3). We lose 204 observations due to missing values, and the WTP is similar to the basic model. The log-likelihood also suggests a better fitting model.

The plot of the WTP distribution is skewed like the other products (Figure 5, top panel) and has what looks like a slight bimodal distribution. The highest WTP value is just under $\$ 20$, which is less than bundles. There is significant heterogeneity here as well. The share of WTP is roughly $99.5 \%$ at $\$ 4$ and $91 \%$ at $\$ 6$. However, the share of WTP drops to $60 \%$ at $\$ 8$ and $34 \%$ at $\$ 10$ (Figure 5, bottom panel). The arc elasticity going to $\$ 10$ is -2.42 , and the share of people willing 

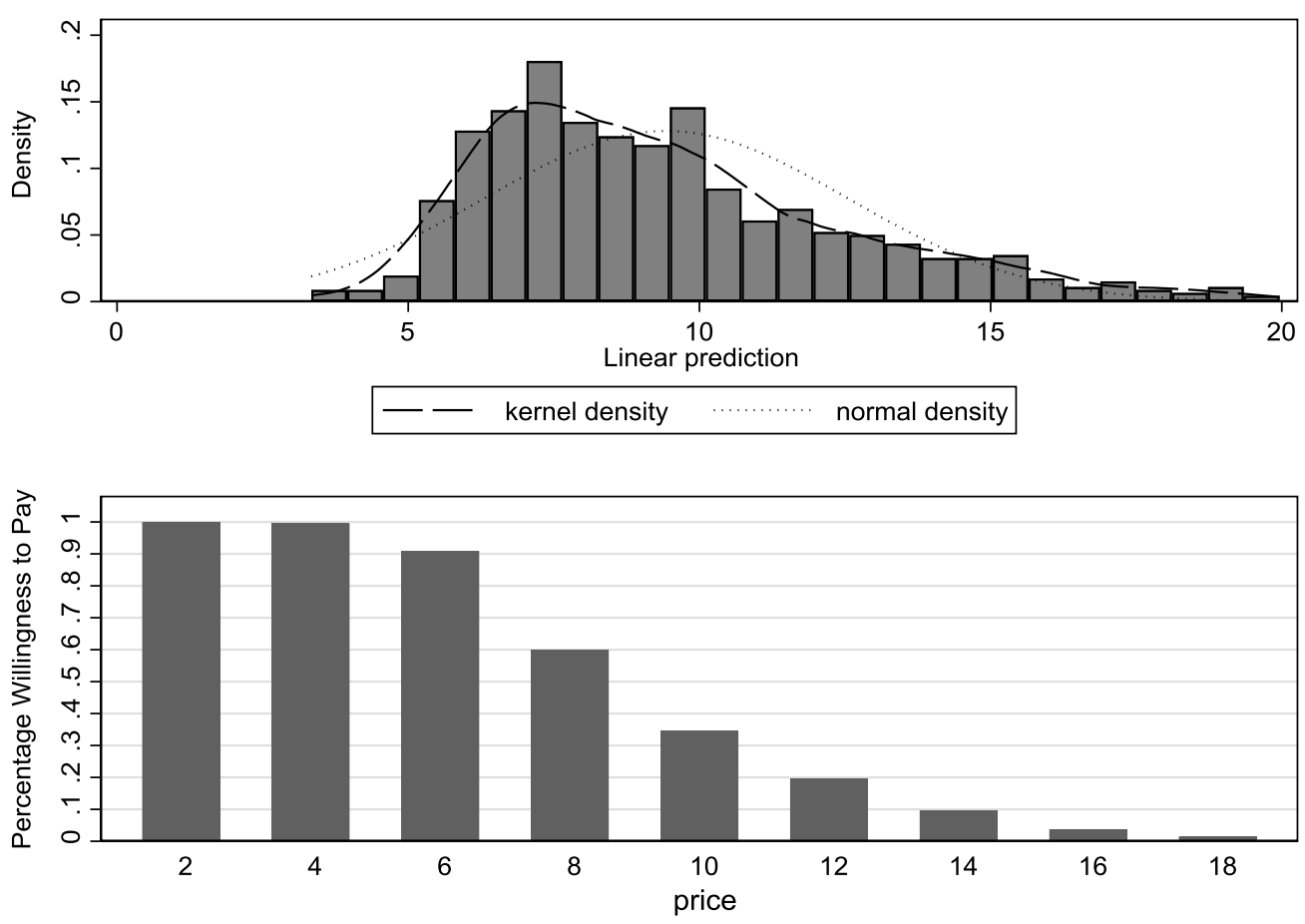

Figure 5. Oil willingness to pay histogram.

to pay $\$ 12$ or more is $<19.5 \%$. Again, growers need to be cautious of raising their prices too high as such elasticity suggests greater losses in sales.

Interestingly, respondent age does not affect WTP for oil, and knowledge of the product has a negative, although insignificant, effect (Table 8, column 3). As purchase frequency increases, so does WTP by $\$ 1.83$, which is the highest of the three products. This can be seen more clearly in the histograms broken out by purchase frequency (Figure 6).

Survey respondents that are familiar with the Georgia Grown marketing program have a higher WTP as do those that shop more frequently at FMs (Table 8, column 3). There is no difference in the WTP based on the perception of local.

\subsection{Product line extensions}

It is possible that survey respondents are interested in purchasing multiple lavender products. In addition, growers may want to consider expanding their product offerings if there is an opportunity to gain more consumers. For instance, a farmer who primarily sells lavender bundles may consider extending their product line to include culinary lavender.

We further explore how consumer awareness and purchase frequency for each of the products affect WTP for specific products. We report only the results of the parameter estimates for consumer awareness and purchase frequency for brevity. As can be seen, all three products have an improved log-likelihood (Table 9), suggesting a better fitting model. Furthermore, the predicted WTP estimates do not change in the new specification.

More interestingly, we find that respondents that purchase lavender oil more frequently have a higher WTP for lavender bundles (0.716) and culinary lavender (0.844) as well as lavender oil. Also, respondents that frequently purchase bundles have a higher WTP for culinary lavender as well (0.894). This indicates that it may be advantageous to target marketing of other lavender 
Table 9. Cross product interest

\begin{tabular}{|c|c|c|c|}
\hline & \multicolumn{3}{|c|}{ Product } \\
\hline & Bundles & Culinary & Oil \\
\hline \multirow[t]{2}{*}{ Unknown bouquet } & -1.912 & -0.776 & -1.74 \\
\hline & -0.08 & -0.22 & -0.11 \\
\hline \multirow[t]{2}{*}{ Purchase freq bouquet } & $1.170^{\star \star}$ & $0.894^{\star \star}$ & 0.85 \\
\hline & -0.00788 & -0.00153 & -0.0617 \\
\hline \multirow[t]{2}{*}{ Unknown culinary } & 0.53 & $-1.081^{\star}$ & 0.523 \\
\hline & -0.55 & -0.05 & -0.57 \\
\hline \multirow[t]{2}{*}{ Purchase freq culinary } & 0.457 & 0.117 & 0.202 \\
\hline & -0.32 & -0.67 & -0.66 \\
\hline \multirow[t]{2}{*}{ Unknown oil } & -0.244 & 1.109 & -1.286 \\
\hline & -0.86 & -0.16 & -0.41 \\
\hline \multirow[t]{2}{*}{ Purchase freq oil } & $0.716^{*}$ & $0.844^{\star \star \star}$ & $1.622^{\star \star \star}$ \\
\hline & -0.03 & -0.00 & -0.00 \\
\hline \multirow[t]{2}{*}{ WTP } & $10.01^{\star \star \star}$ & $5.551^{\star \star \star}$ & $9.45^{\star \star \star}$ \\
\hline & -0.23 & -0.13 & -0.24 \\
\hline Observations & 735 & 734 & 737 \\
\hline Log-lik & -916.9 & -893 & -870.6 \\
\hline
\end{tabular}

${ }^{\star * *} P<0.001,{ }^{* \star} P<0.01,{ }^{*} P<0.05$

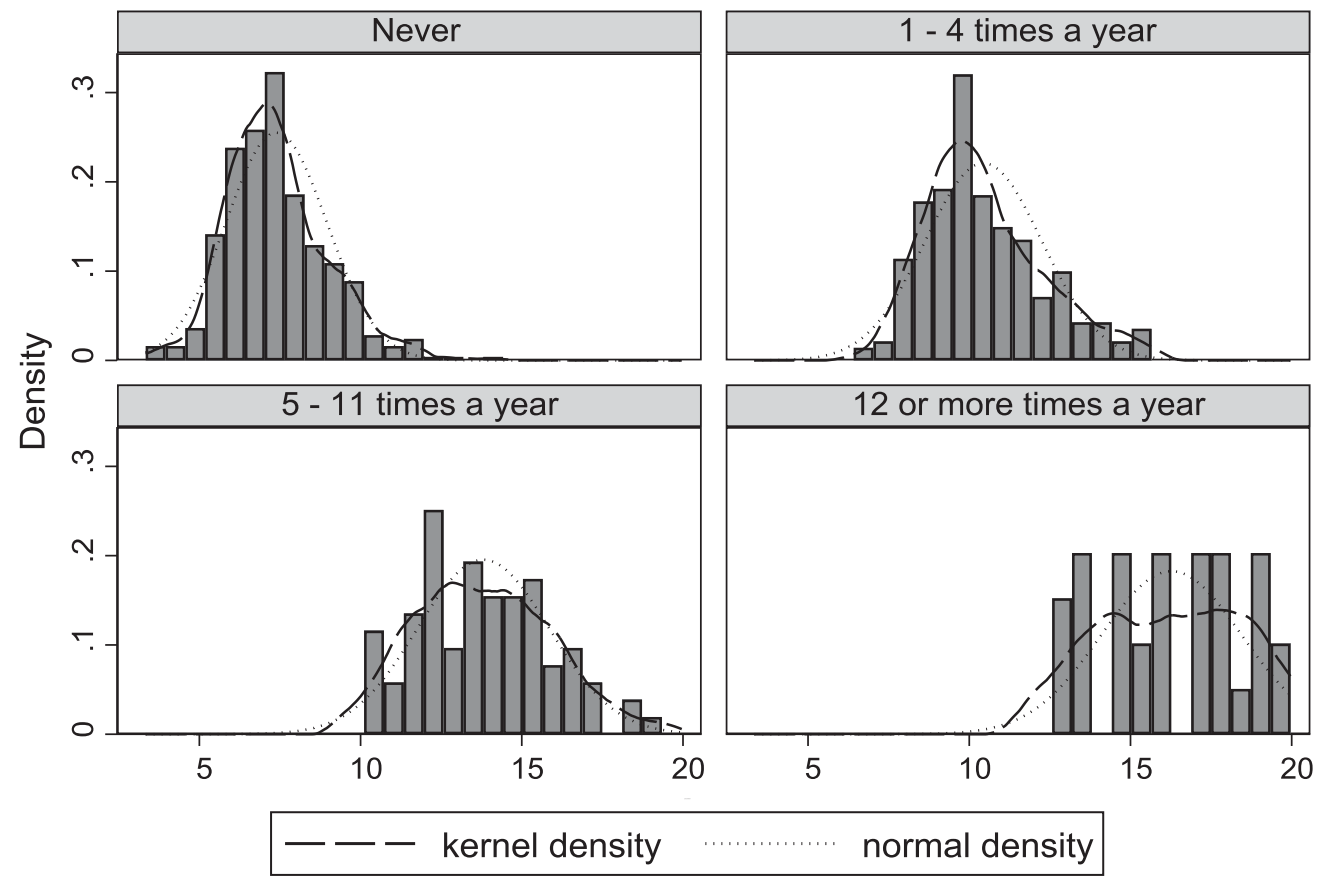

Graphs by freq_oil

Figure 6 . Oil willingness to pay histogram by purchase frequency. 
products toward lavender oil customers and to a lesser degree, lavender bundle customers. Alternatively, the culinary lavender consumers in our data set do not appear to have as much interest in purchasing other lavender products.

\section{Discussion}

We find that consumer WTP is highest for lavender bundles and lowest for culinary lavender. The production and processing of lavender bundles are straightforward and require only cutting and drying. Alternatively, lavender oil requires processing and storage. Therefore, whereas it has a higher WTP than culinary lavender, it may be more costly to produce as well. This is an important consideration for any grower entering the market.

A key finding of our analysis indicates that WTP increases significantly based on purchase frequency. Furthermore, survey respondents that seldom or never purchase a product have a lower WTP. Intuitively, this suggests that familiarity with the product may result in higher personal valuation. In some cases, our survey respondents had no idea what the lavender product was.

These findings suggest that educating consumers about lavender and lavender-based products could have an immediate impact on WTP. In the case of culinary lavender and lavender oil, this may be especially relevant as people may not have any idea about how to use these products in their lives. In addition, marketing tactics that increase purchase frequency with existing users could also be beneficial. This could include provide strategies for how to more often use lavender. As an example, one grower we spoke with discussed how culinary lavender is often used as a substitute for rosemary in recipes or as part of a tea packet. Providing such knowledge to customers could help increase consumer demand or WTP.

The distribution of WTP estimates also suggests that respondents are fairly price elastic. As such, growers must be careful about pricing too high to the "wrong" consumers. To this point, we find that respondents who are knowledgeable about state marketing programs like Georgia Grown and who shop more at FMs have a higher WTP. This identifies a specific type of consumer that could be more valuable for growers to target.

Perhaps, a more important consideration is the viability of the lavender market as a whole. At the time of this study, lavender occupies a niche market in the south and Georgia. Furthermore, it is not clear how much the market can expand, which is beyond the scope of this study. Growers and producers need to be cognizant of market saturation for marketing and selling locally grown horticulture.

We limited our study to three products that are commonly sold by lavender producers. There is a greater diversity of lavender-based products that could provide potential value for growers beyond these products. Furthermore, marketing such products to on-site consumers, for instance, at an agritourism location, could provide additional value as well. Future studies may consider such opportunities.

We acknowledge that there are limits to stated preference studies with respect to hypothetical bias and external validity of the results. Furthermore, our sample is a convenience sample that is recruited and compensated for their time. Further work on actual purchase behavior would provide further insight into consumer preferences for lavender.

Acknowledgments. We would like to thank Vanessa Shonkwiler and multiple graduate students in the Department of Agricultural and Applied Economics at the University of Georgia for their input on the survey design. We would also like to thank Georgia Lavender growers for their input on this research project. Finally, the authors thank participants at the Southern Agricultural Economics Association Annual meeting for their feedback.

Financial disclosure. This research was funded by the USDA Specialty Crop Block Grant Program, administered by the Georgia Department of Agriculture. Grant number 16-SCBGP-GA-0010.

Conflicts of interest. None. 


\section{References}

Adam, K.L. Lavender Production, Products, Markets, and Entertainment Farms. Butte, MT: ATTRA-National Sustainable Agriculture Information Service, November 2006.

Chakrabarti, A., B. Campbell, and V. Shonkwiler. "Eliciting Consumer Preference and Willingness to Pay for Specialty Mushrooms: Using a Latent Class Approach.” Journal of Food Distribution Research 50(2019):46-62.

Collart, A.J., M.A. Palma, and C.E. Carpio. "Consumer Response to Point of Purchase Advertising for Local Brands." Journal of Agricultural and Applied Economics 45(2013):229-242.

Darby, K., M.T. Batte, S. Ernst, and B. Roe. "Decomposing Local: A Conjoint Analysis of Locally Produced Foods." American Journal of Agricultural Economics 90(2008):476-86.

Ekanem, E., M. Mafuyai, and A. Clardy. "Economic Importance of Local Food Markets: Evidence from the Literature." Journal of Food Distribution Research 47(2016):57-64.

Flagg, L.A., B. Sen, M. Kilgore, and J.L. Locher. "The Influence of Gender, Age, Education, and Household Size on Meal Preparation and Food Shopping Responsibilities." Public Health Nutrition 17(2013):2061-70.

Gao, G., and B. Bergefurd. "Culinary Herbs as Alternative Cash Crops for Small Scale Farmers in Southern Ohio." Journal of Extension 36(1998):6.

Hanemann, M., J. Loomis, and B. Kanninen,. "Statistical Efficiency of Double-Bounded Dichotomous Choice Contingent Valuation.” American Journal of Agricultural Economics 73(1991):1255-63.

Hawkins, G., S.E. Burnett, and L.B. Stack. "Survey of Consumer Interest in Organic, Sustainable, and Local Container-grown Plants in Maine." HortTechnology 22(2012): 817-825.

Katz, M., B. Campbell, and Y. Liu. "Local and Organic Preference: Logo versus Text." Journal of Agricultural and Applied Economics 51(2019):328-47.

Khachatryan, H., A. Rihn, B. Campbell, B. Behe, and C. Hall. "How Do Consumer Perceptions of "Local" Production Benefits Influence Their Visual Attention to State Marketing Programs?" Agribusiness 34(2018):390-406.

Kim, M., K.R. Curtis, and I. Yeager. “An Assessment of Market Strategies for Small-Scale Produce Growers.” International Food and Agribusiness Management Review 17(2014):187-204.

Lopez-Feldman, A. "Introduction to Contingent Valuation Using Stata." Working paper, Munich Personal RePEc Archive, MPRA paper no. 41018, September 4, 2012.

Low, S.A., A. Adalja, E. Beaulieu, N. Key, S. Martinez, A. Melton, and B. Jablonski. Trends in US Local and Regional Food Systems: A Report to Congress. Washington, DC: U.S. Department of Agriculture, Economic Research Service, Administrative Publication No. AP-068, 2015.

Onozaka, Y., and D.T. McFadden. "Does Local Labeling Complement or Compete with Other Sustainable Labels? A Conjoint Analysis of Direct and Joint Values for Fresh Produce Claims." American Journal of Agricultural Economics 93(2011):693-706.

Palma, M.A., K. Morgan, T. Woods, and S. McCoy. "Response of Land Grant Universities to the Increase in Consumer Demand for Local Foods in the South." Choices 28,4(2013):1-5.

Reynolds-Allie, K., D. Fields, and R. Rainey. "Risk Management Issues for Small Fruits within Local Food Systems." Choices 28(2013):1-4.

Rihn, A., H. Khachatryan, B. Campbell, C. Hall, and B. Behe. "Consumer Preferences for Organic Production Methods and Origin Promotions on Ornamental Plants: Evidence from Eye-tracking Experiments.” Agricultural Economics 47(2016):599-608.

Rogers, M.A., and H.W. Kerr, Jr. Herbs: A Small-Scale Agriculture Alternative. Davis, CA: University of California Small Farm Program, 1995. http://sfp.ucdavis.edu/pubs/brochures/Herbs/

Starr, A., A. Card, C. Benepe, G. Auld, D. Lamm, K. Smith, and K. Wilken. "Sustaining Local Agriculture Barriers and Opportunities to Direct Marketing between Farms and Restaurants in Colorado." Agriculture and Human Values 20(2003):301-321.

United States Census Bureau. “American Fact Finder,” 2019a. Internet site: https:/factfinder.census.gov/faces/nav/jsf/pages/ community_facts.xhtml (Accessed June 30, 2019).

United States Census Bureau. "QuickFacts," 2019b. Internet site: https://www.census.gov/quickfacts/fact/table/US/ INC110217 (Accessed June 30, 2019).

Vogel, S., and S.A. Low. “The Size and Scope of Locally Marketed Food Production.” Amber Waves (2015): 1.

Wolfe, A. "Christine Lagarde: On Top of the World." The Wall Street Journal. Internet site: https:/www.wsj.com/articles/christinelagarde-on-top-of-the-world-1380934428 (Accessed December 19, 2019).

Yue, C., and C. Tong. "Organic or Local? Investigating Consumer Preference for Fresh Produce Using a Choice Experiment with Real Economic Incentives.” HortScience 44(2009):366-71.

Yue, C., J.H. Dennis, B.K. Behe, C.R. Hall, B.L. Campbell, and R.G. Lopez. "Investigating Consumer Preference for Organic, Local, or Sustainable Plants." HortScience 46(2011):610-615.

Zepeda, L. "Which Little Piggy goes to Market? Characteristics of US Farmers' Market Shoppers." International Journal of Consumer Studies 33(2009):250-7.

Zepeda, L., and J. Li. "Who Buys Local Food?" Journal of Food Distribution Research 37(2006):1-11. 


\section{Appendix}

\begin{tabular}{|c|c|}
\hline Variable & Description \\
\hline \multirow[t]{8}{*}{ Education } & Less than high school \\
\hline & High school or GED \\
\hline & Some college \\
\hline & 2-year college degree \\
\hline & 4-year college degree \\
\hline & Master's degree \\
\hline & Doctoral degree \\
\hline & Professional degree (JD, MD) \\
\hline \multirow[t]{11}{*}{ Income } & Less than $\$ 25,000$ \\
\hline & $\$ 25,001-\$ 50,000$ \\
\hline & $\$ 50,001-\$ 75,000$ \\
\hline & $\$ 75,001-\$ 100,000$ \\
\hline & $\$ 100,001-\$ 125,000$ \\
\hline & $\$ 125,001-\$ 150,000$ \\
\hline & $\$ 150,001-\$ 175,000$ \\
\hline & $\$ 175,001-\$ 200,000$ \\
\hline & $\$ 200,001-\$ 225,000$ \\
\hline & $\$ 225,001-\$ 250,000$ \\
\hline & $\$ 250,001$ or more \\
\hline State residence & $\mathrm{AL}, \mathrm{GA}, \mathrm{FL}, \mathrm{SC}, \mathrm{TN}$ \\
\hline \multirow[t]{6}{*}{ Purchase frequency } & How often do you buy... < product $>$ \\
\hline & I do not know what this is \\
\hline & Never \\
\hline & 1-4 times a year \\
\hline & 5-11 times a year \\
\hline & 12 or more times a year \\
\hline \multirow[t]{6}{*}{ Georgia Grown } & How familiar are you with the Georgia Grown Marketing program? \\
\hline & I have not heard of it \\
\hline & I have heard of it, but do not know what it is \\
\hline & Somewhat familiar with the program \\
\hline & I am familiar with the program \\
\hline & I am very familiar with the program \\
\hline
\end{tabular}


Appendix (Continued)

\begin{tabular}{|c|c|}
\hline Variable & Description \\
\hline \multirow[t]{6}{*}{ Farmers' market } & How often do you shop at farmers' markets during the summer? \\
\hline & 0 times a summer \\
\hline & 1-2 times a summer \\
\hline & 3-5 times a summer \\
\hline & $6-12$ times a summer \\
\hline & 13 times or more a summer \\
\hline \multirow[t]{7}{*}{ Local } & What is the largest geographic area that you would consider food to be called locally grown? \\
\hline & The town you live in \\
\hline & The county you live in \\
\hline & The region you live in (e.g., Piedmont, South Georgia, Coastal Plain, etc.) \\
\hline & The state you live in \\
\hline & The southeast \\
\hline & The United States \\
\hline
\end{tabular}

Cite this article: Berning J, Campbell B, and Buttshaw J (2020). Assessing Consumer Demand for Georgia Lavender-Based Products. Journal of Agricultural and Applied Economics 52, 461-479. https://doi.org/10.1017/aae.2020.10 